\title{
AUTOPSY FINDINGS IN A CASE OF PITUITARY DWARFISM
}

\author{
BY
}

\author{
A. T. SANDISON \\ From the Departments of Pathology, the University and Western Infirmary, Glasgow
}

(RECEIVED FOR PUBLICATION MARCH 20, 1958)

Although the condition of pituitary dwarfism has been recognized for some considerable time, there is still a relative lack of published autopsy findings and the following case is reported briefly for this reason.

Lack of hypophysial growth hormone (almost certainly elaborated in the alpha cells of the pars anterior) during infancy or childhood results in varying degrees of under-development which may range from obvious dwarfism to slight degrees of lack of normal stature. In some cases, so-called primordial dwarfs may be small at birth and grow at a much reduced rate, while in others the child may grow normally for a varying period of time.

The term infantilism, sometimes used synonymously with dwarfism, may more strictly be applied to individuals in whom there is impairment of growth, sexual development and intellect while nanism implies restriction of growth in stature only. Infantilism is often referred to as the Levi-Lorain syndrome, the condition having been described by Lorain (1871) and by Levi (1908). Post-mortem studies are infrequent since the uncomplicated condition is not incompatible with good health. In childhood the patient is perfectly formed but somatic growth is slow. Development of the primary and secondary sexual phenomena does not occur at puberty and the genitalia usually remain infantile. This is not invariable, however, and some limited degree of sexual development may occur. Epiphyseal closure may be delayed but the ultimate stature attained is considerably below normal due to lack of growth hormone. Purely intellectual development may be satisfactory but emotional and behaviour patterns may be immature. These patients are slender with graceful limbs, ankles and wrists, and they often have fine, smooth skin and soft silky hair (Price, 1946).

Hypophysial dwarfs are usually born of normal parents, and some cases are recorded of hypophysial dwarfs producing normal offspring. They show good body symmetry, the physique being that of early childhood in which the lower measurements are relatively short. Most are thin and obesity is rather uncommon. The genitalia are generally under-developed and the secondary sexual characteristics may be absent or retarded. There may be amenorrhoea in the female and azoospermia in the male. Nevertheless, as indicated above, hypophysial dwarfs may occasionally be fertile. The skeletal framework is smaller and more fragile than normal and epiphyseal closure tends to be delayed. The appetite may be small and the basal metabolic rate low. There is not the profound impairment of the central nervous system noted in cretins, nor does one see the myxoedematous infiltration of subcutaneous or submucous tissues present in juvenile myxoedema. The metabolic consequences of adrenal hypoplasia are much less conspicuous than in Addison's disease. Glucose tolerance is sometimes increased. Occasionally radiography may show a small sella turcica but this is not common; indeed the sella may be enlarged due to adenoma or craniopharyngioma. It has been suggested that the term ateleiosis might well be used for the generality of dwarfism until the true extent of hypopituitarism in the causation of these cases is established (Cecil and Loeb, 1955).

For full consideration of types of dwarfism reference may be made to Wilkins (1950). Many of the points made above are confirmed and some further suggestions are put forward. Wilkins points out that androgen deficiency may be shown by low levels of 17-ketosteroids and by the relative absence of body hair. Often the testes and ovaries are immature and there is a low level of folliclestimulating hormone. The facies is childish and immature but with attainment of the fourth decade a peculiar 'oldish-young' look may appear due to atrophy and wrinkling of the skin.

The pathology of this condition was first discussed by Erdheim $(1916,1925)$ who introduced the term 
'nanosomia pituitaria'. Reference may be made also to Kraus (1926). Brief discussions are given in the textbooks of Cappell (1951) and Anderson (1953). Among the commoner causes of pituitary nanosomia are intra- or extra-cellular craniopharyngioma which may show marked retrogression. Other conditions described are fibrosis of the pars anterior (possibly ischaemic in origin), colloid-cystic degeneration, congenital syphilis, chronic hydrocephalus and hypophysial malformation. Russfield and Reiner (1957) have described three cases of dwarfism without mechanical destruction of the pituitary and postulate possible failure of production of growth hormone by so-called 'amphophil' cells. The thyroid gland may be atrophic but the parathyroids, which are probably not under hypophysial control, are unaffected. The adrenals may be small and occasionally diabetes mellitus or even diabetes insipidus has been described. The latter condition would suggest possible hypothalamic damage; hypothalamic damage may undoubtedly be responsible for obesity when this is present. It seems probable that lack of alpha cells leads to growth impairment while beta cell insufficiency is responsible for genital dystrophy. Cappell has pointed out that in the Lawrence-Moon-Biedl syndrome there is evidence of a hereditary influence, the dwarfism here being associated with retinitis pigmentosa and polydactyly.

In the case now to be described a 15-year-old girl died from malignant astrocytoma. An associated dwarfism was the result of pituitary hypoplasia and of the presence of chromophobe adenoma and developmental cyst in the small pars anterior.

\section{Case History}

The patient, a 15-year-old girl, was admitted to the wards of Dr. J. A. W. McCluskie at the Western Infirmary, Glasgow. She was the fifth child of normal parents, the siblings being normal, alive and well. Parturition was two months premature and the patient then weighed $1.6 \mathrm{Kg}$. Mental and physical growth was from the first retarded and all the landmarks of development were delayed in appearance. At the age of 22 months she weighed only $6.0 \mathrm{Kg}$. instead of the expected $11.0 \mathrm{Kg}$. At this time she was seen by Professor Stanley Graham at the Royal Hospital for Sick Children, Glasgow, and was then noted to be mentally backward. Her height was $65 \mathrm{~cm}$. (normal $80 \mathrm{~cm}$.) and the circumference of the head was $39 \mathrm{~cm}$. (normal $47 \mathrm{~cm}$.). The cranial sutures were well united. At this time a course of antuitrin $G$ was given without obvious effect.

By the age of 30 months she could walk without aid but intelligible and coherent sentences were not formulated until the age of 7 years. During the four years before admission there had been little or no somatic growth but the patient was able to undertake simple domestic tasks. At the age of 13 years, for a period of three months only she menstruated, apparently normally, but thereafter amenorrhoea was invariable. There was, however, some development of secondary sexual characteristics.

Some five weeks before admission the patient fell heavily and was dazed for a short time. Two weeks later her behaviour suggested gross visual defect and she became inactive. Aphasia and incontinence then developed although after a time some capacity for speech returned.

On examination, the patient proved to be imbecile and uncooperative. The hands and feet were small, the maximum circumference of the head was $44 \mathrm{~cm}$. and the distance from the anterior superior iliac spine to the internal malleolus was $55 \mathrm{~cm}$. There was bilateral webbing of the second and third toes. The teeth were of primary dentition and in poor condition. The palate was normal, as were the ear drums. The left pupil was larger than the right; neither reacted to light and both lenses were rather opaque. The tendon reflexes were difficult to elicit but the plantar responses were flexor.

The erythrocyte sedimentation rate was $6 \mathrm{~mm}$. in the first hour. The Wassermann reaction was negative. The white blood count was $16500 / \mathrm{c} . \mathrm{mm}$. with a polymorphonuclear leucocytosis. A radiograph of the chest was negative: the skull was small but showed no abnormality; the bones of the forearm were normally ossified. Lumbar puncture showed an opalescent fluid under pressure. Cells were 650 polymorphs per c.mm. Sugar was $68.0 \mathrm{mg}$. \%; protein, $160 \mathrm{mg}$. \%; chlorides, $708 \mathrm{mg}$. $\%$. There was no growth on culture and tubercle bacilli were not demonstrated. Despite intrathecal penicillin and oral sulphadimidine the condition of the patient deteriorated and she died $\mathbf{1 0}$ days after admission.

Post-Mortem Examination (Dr. J. M. Johnstone). The body length was about $120 \mathrm{~cm}$., the mean for a girl of this age being $161 \mathrm{~cm}$. The head, hands and feet were small but well-formed and the limbs in proportion to the trunk. The fingers were of 'spindle' type. The facial appearance was older than the stated age suggested. The trunk was rather obese and the breasts were low hemispheres with poorly developed nipples and areolae. On dissection they proved to be largely fatty. The pubic hair was normal but axillary hair was scanty.

The heart $(110 \mathrm{~g}$.) showed no congenital defects and the lungs (left, $120 \mathrm{~g}$.; right, $95 \mathrm{~g}$.) were normal. The alimentary tract, liver (440 g.), spleen $(40 \mathrm{~g}$.) and kidneys (each 30 g.) showed no evidence of acquired disease. The uterus was infantile and the ovaries small without obvious follicle or corpus luteum formation. The adrenals and thyroid were small. No parathyroid adenoma was discovered.

The brain was congested and the convolutions were flattened. There was bulging of the left frontal lobe; this proved to be due to a haemorrhagic, necrotic tumour with central cystic degeneration which occupied the whole frontal lobe, extended back to the left caudate nucleus and crossed into the right frontal lobe for a little way 


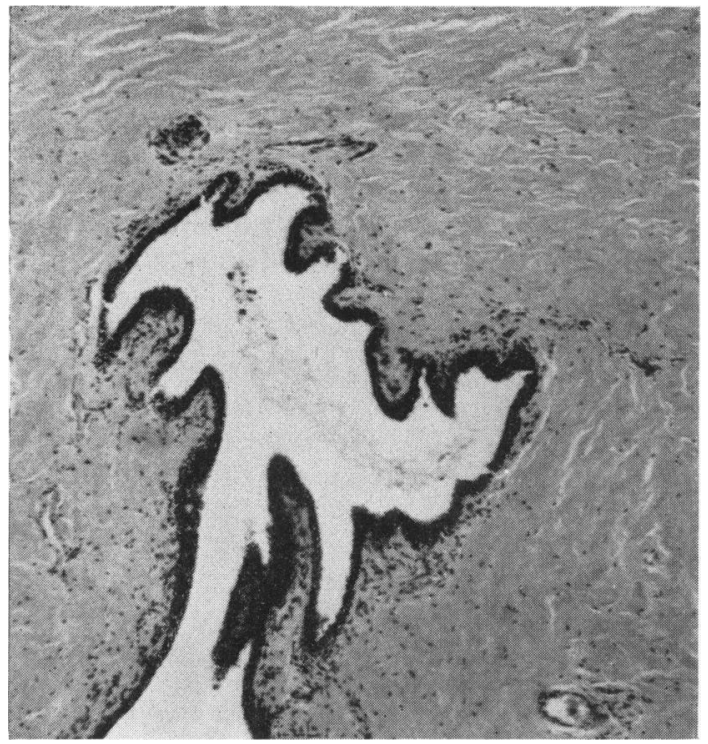

FIG. 1.-Section of breast to show simple duct system without evidence of lobule formation. Haemalum and eosin. $\times 75$.

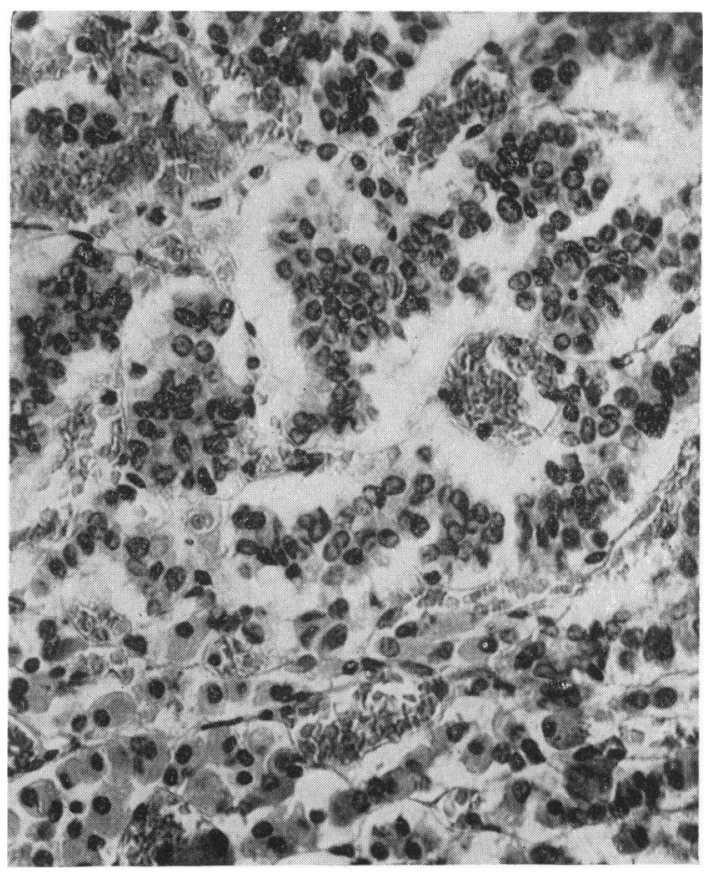

FIG. 2.-Chromophobe adenoma of pituitary with normal chromophil cells of pars anterior at the bottom. Picromallory stain. $\times 420$. via the anterior commissure. The optic nerves and chiasma appeared normal. The pituitary was small.

Histological Examination (A. T. Sandison). The heart, lungs, liver, spleen and kidneys showed no significant change. The pancreatic islets appeared normal. The thyroid acini contained abundant well-stained colloid and were lined by cuboidal epithelium. Parathyroid and adrenals showed no structural abnormality. The breasts were largely fatty but in the fibrous strands there were ducts of simple immature type without evidence of lobule formation (Fig. 1). The ovarian cortical stroma was only moderately cellular; a few small ripening follicles of immature appearance were seen. The cervix uteri was normal and the endometrium appeared inactive with some dilatation of the glands.

The cerebral neoplasm was a highly cellular, vascular and necrotic astrocytoma producing little or no glia. The cells varied from spheroidal to spindle-cell type but mitotic activity was not great.

PItUitary. This was hypoplastic, the mid-level horizontal cross-sectional area being about two-thirds of that of some glands from females of similar age. The pars anterior was greatly congested with prominent vascular spaces. One lateral lobe was occupied by a rather haemorrhagic, trabeculated, small-cell chromophobe adenoma with protein-containing fluid between the trabeculae (Fig. 2). The chromophobe cells present

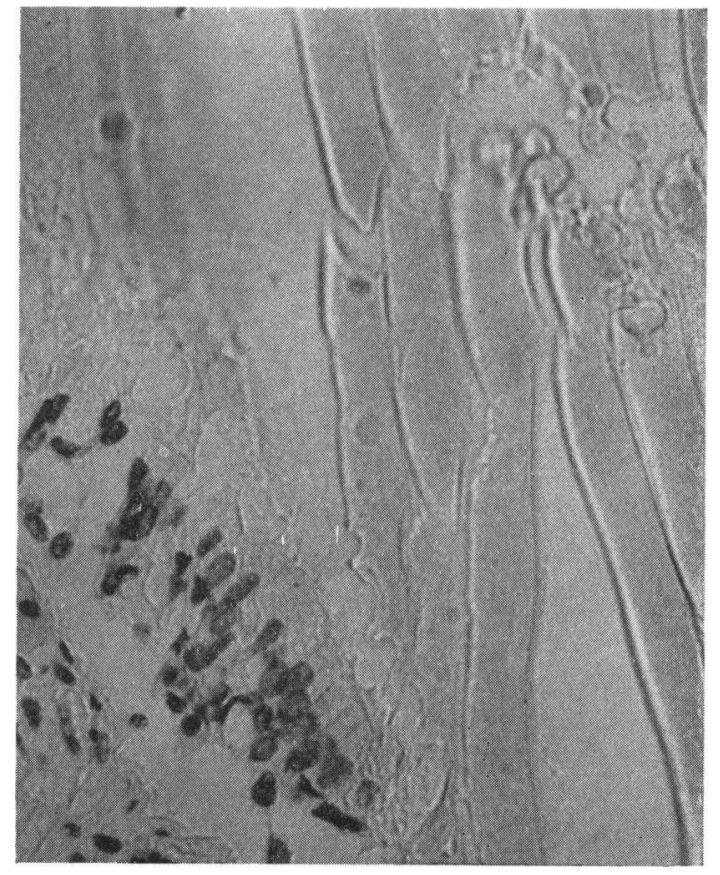

FIG. 3.-Developmental cyst of pars anterior containing colloid-like substance and lined by ciliated epithelium. Heidenhain's iron haematoxylin. $\times 420$. 
contained no granules stainable by the perjodic-acid Schiff method. The opposite lateral area was largely occupied by a colloid-containing cyst which was lined partly by cubical and partly by tall columnar ciliated epithelium (Fig. 3). The remaining parenchyma contained well-granulated alpha and beta cells which were arranged rather haphazardly. The nature of these cells was confirmed by staining with the Mallory, phosphotungstic-acid haematoxylin, eosin-methylene blue and McLetchie and Pearse methods.

\section{Discussion}

The cause of death in this child was a malignant astrocytoma of the left frontal region which had produced obvious clinical effects for a period of six to seven weeks only. The patient, however, had been small at birth and had failed to grow normally; no increase in stature had been noticed in the four years before death. Mental development had also been retarded considerably although she could carry out simple domestic tasks. It is interesting to recall that the patient had menstruated three times at the age of 13 years but that this had not again occurred. Pubic hair developed despite the infantile genitalia but the breasts, although at first sight normal, were largely fatty. The normal developing breast at this age is a fibrous cone enveloped at the periphery by fat. Furthermore, the breast parenchyma was immature on histological examination.

The dwarfism here was of proportionate type and associated with mental retardation and poor development of sexual characteristics. This picture is not inconsistent with pituitary insufficiency and this was substantiated by histological examination. The pituitary in this instance was hypoplastic. Furthermore, a considerable bulk of the gland was occupied by a simple chromophobe adenoma and by a cyst of developmental Rathke type as shown by the ciliated lining. These abnormalities must have further reduced the volume of functional pars anterior. Undoubted alpha and beta cells were demonstrated in rather haphazard arrangement but these must have been inadequate for the production of sufficient growth hormone and gonadotrophins.

\section{Summary}

A 15-year-old girl who died of malignant astrocytoma was a dwarf of proportionate type from birth. There was also retarded mental development and poor sexual development. This dwarfism was the result of hypoplasia of the pituitary gland, the pars anterior of which was largely occupied by a simple chromophobe adenoma and a developmental cyst.

My thanks are due to Dr. J. A. W. McCluskie for permission to publish this case and to Dr. J. M. Johnstone for allowing me to quote from his autopsy records. I am also grateful to Mr. N. L. Russell for technical assistance and to Mr. W. Mason for the photographs.

\section{REFERENCES}

Anderson, W. A. D. (1953). Pathology, 2nd ed. London.

Cappell, D. F. (1951). Muir's Textbook of Pathology, 6th ed. London.

Cecil, R. L. and Loeb, R. F. (1955). Textbook of Medicine, 9th ed. Philadelphia and London.

Erdheim, J. (1916). Beitr. path. Anat., 62, 302

(1925). Ergebn. allg. Path. path. Anat., 21, 482.

Kraus, E. J. (1926). In Henke and Lubarsch Handbuch der Spezielle Pathologischen Anatomie und Histologie, 8, 899.

Levi, E. (1908). Nouv. Inconogr. Salpêt., 21, 297, 421.

Lorain (1871). Lettre préfacée à la thèse de Faneau de la Cour. Du féminisme et de l'infantilisme chez les tuberculeux. Paris.

Price, F. W. (1946). A Textbook of the Practice of Medicine, 7th ed. London.

Russfield, A. B. and Reiner, L. (1957). Lab. Invest., 6, 334.

Wilkins, L. (1950). The Diagnosis and Treatment of Endocrine Disorders in Childhood and Adolescence. Springfield, Illinois. 